\title{
A novel approach to solve the water saturation challenges in reservoirs under LoSal water injection
}

\author{
Moustafa Oraby $^{1} \cdot$ Mohamed Khairy $^{1} \cdot$ Marwan Moussa $^{1}$
}

Received: 25 July 2020 / Accepted: 23 October 2020 / Published online: 6 November 2020

(c) The Author(s) 2020

\begin{abstract}
Enhancing hydrocarbon recovery is an ongoing practice in the petroleum industry. Multiple approaches are developed and proved their effectiveness in increasing reservoirs recovery. One of the recent approaches is the Low Salinity Water Injection which is known in the industry by "LoSal". The determination of the optimum low salinity of the injected water and the mechanism behind its ability to enhance the hydrocarbon recovery are still the subjects of interest for many researchers and industry professionals. Despite the value of the LoSal water injection, it brings with it a considerable challenge to the future formation evaluation, namely the determination of the fluids' saturation. The mixing of the low salinity injected water with the original high-salinity formation water creates variable water salinity across the reservoir. This is known in the industry by the "mixed-salinity" problem. The horizontal and the vertical heterogeneity of the permeability and porosity across the reservoir is the main factor that controls the "mixed-salinity" distribution in the injected volume. The challenge of calculating the fluids' saturation exists for both the infill drilling wells and the monitoring wells. For the infill drilling wells, the saturation calculations require accurate formation water resistivity values, $R_{w}$, which became variable due to the mixed-salinity. For the monitoring wells, the fluids saturation calculations require accurate formation water sigma absorption, $\Sigma_{w}$, which also became variable for the same reason. The inability to determine the current $R_{w}$ and $\Sigma_{w}$ on foot-by-foot basis results in incorrect calculations of the water and hydrocarbon saturations. This creates an economic burden on the reservoir management. The existing methods to interpret the fluids saturation in mixed-salinity reservoirs face the challenges of accuracy, effect of borehole environment and high-data acquisitions cost. A forward modeling is developed to illustrate the problem and its impact on the reservoir decisions making process. A solution to the challenges is proposed, investigated, and proved both theoretically and in the laboratory. The proposed solution is based on lowering the LoSal water resistivity, prior to injection, to be equal to the original formation water resistivity without changing its low salinity. This is achieved by mixing the LoSal water with either acid or alkaline based on the reservoir condition. The acid or alkaline will reduce the resistivity of the LoSal water while keeping its low salinity unchanged. The determination of the required volume of the acid or the alkaline is calculated using the conductivity mixing law and the solution is tested on core plugs. The possible effects of the acid on the formation lithology, specially the clay content is discussed and proved to be negligible due to the very low acid volume required. This is also supported by previously published measurements.
\end{abstract}

Keywords Enhanced oil recovery $\cdot$ Low salinity enhanced oil recovery $\cdot$ Mixed salinity reservoirs $\cdot$ Water injection

\section{Introduction}

The low salinity water injection, LoSal is the subject of interest for many scientists and industry professionals to enhance the reservoirs recovery factors. The LoSal creates

Moustafa Oraby

moustafa.oraby@aucegypt.edu

1 American University in Cairo, Cairo, Egypt a distribution of mixed-salinity water, horizontally and vertically, across the reservoirs. The mixed-salinity water represents a challenge to the open-hole and the cased-hole water saturation models.

Currently, two different approaches are used in the industry to overcome the mixed-salinity challenges in formation evaluation. The two approaches can be summarized as.

1. Develop a technology, insensitive to the water salinity, to calculate the formation water saturation. This approach 
resulted in developing the Carbon/Oxygen tool, known as $\mathrm{C} / \mathrm{O}$ tool. This technology is suited for the cased-hole monitoring wells, but some also use it in the open-hole wells under certain conditions.

2. Acquire multiple measurements to simultaneously solve for both water saturation and water salinity

\section{The first approach}

The Carbon/Oxygen, $\mathrm{C} / \mathrm{O}$, tool was introduced in the early 1960 and went through multiple developments until late 1980. To determine the water saturation, the $\mathrm{C} / \mathrm{O}$ tool uses the ratio between the inelastic gamma rays emitted by the carbon and the oxygen atoms after colliding with high energy neutrons. Since the inelastic gamma ray is independent of the water salinity, the $\mathrm{C} / \mathrm{O}$ can be used to determine the water saturation in mixed-water salinity reservoirs.

In 1989, Freeman and Fenn (1989) investigated the ability of the Carbon/Oxygen tool in determining the water saturation and the residual oil saturation in unknown formation water salinity reservoirs in the Middle East. The calculated water saturation and oil saturation using the $\mathrm{C} / \mathrm{O}$ tool is compared to the extracted fluids from the sponge core. Based on the log-to-core comparison, they concluded that the $\mathrm{C} / \mathrm{O}$ tool should be only used when the formation porosity is higher than $15 \%$ and the formations are not affected by any mud filtrate. This conclusion puts a strong limitation on the $\mathrm{C} / \mathrm{O}$ tools applications.

In 2004, Eyvazzadeh et al. (2004) performed a comparison between the different $\mathrm{C} / \mathrm{O}$ tools for the different service providers. The core of the study included tools design, interpretation methods, limitations, and accuracies. They concluded that the $\mathrm{C} / \mathrm{O}$ tool requires careful job planning for every application to ensure best data quality and increase the confidence in the interpretation results. They also concluded that due to the differences in tools design between the different service companies, there is no unique solution obtained. They attributed this to the variations in the effects of the borehole conditions such as cements, casing, fluid types, etc., on the different tools. Eyvazzadeh et al.'s conclusions raised the concerns regarding the confidence in the interpretation results and the need for a specialized interpreter to plan and interpret every well.

In 2005, Ma et al. (2005) compared the applications of multiple technologies namely, the through casing resistivity, the Sigma measurement, and the $\mathrm{C} / \mathrm{O}$ measurement in determining the remaining oil saturation in mixed-salinity carbonate reservoirs in the Middle East. Based on Ma et al., the $\mathrm{C} / \mathrm{O}$ tool should not be used for any reservoir with porosity less than $15 \%$, as previously found by Freeman et al., and for any wells with washout or formation damage, similar to the conclusion of Eyvazzadeh et al. These limitations are impractical for many reservoirs and impose serious
Table 1 Comparison of resistivity and nuclear logging for RSM, modified after Aulia et al. 1

\begin{tabular}{|l|l|l|l|l|}
\hline \multicolumn{1}{|c|}{ Condition } & C-O & $\Sigma$ & $R_{I}$ & \multicolumn{1}{|c|}{ Remarks } \\
\hline$\phi<15 \%$ & & & & Limit on $R_{T, \max }$ \\
\hline $15 \%<\phi<30 \%, C_{\text {salt }}<20 \mathrm{ppk}$ & & & & Limit on $R_{T, m a x}$ \\
\hline $15 \%<\phi<30 \%, C_{\text {salt }}>20 \mathrm{ppk}$ & & & & \\
\hline High $\phi \& C_{\text {salt }}$ & & & & \\
\hline Mixed-salinity & & & & $\begin{array}{l}R_{T} \text { qualitative, } \\
\text { unless } C_{\text {salt }} \text { is known }\end{array}$ \\
\hline Very low $S_{w}$ & & & & Limit on $R_{\mathrm{T}, \max }$ \\
\hline Run in small tubing & & & & Need slim tool \\
\hline Washed-out holes & & & & $\begin{array}{l}\text { Effect on shallow } \\
\text { nuclear logging }\end{array}$ \\
\hline Flowing wells & & & & $\begin{array}{l}\text { Effect of hold-up on } \\
\text { C-O }\end{array}$ \\
\hline Fluid contacts in hole & & & & Effect on C-O \\
\hline Near wellbore effects & & & & $\begin{array}{l}\text { Effect on shallow } \\
\text { nuclear logging }\end{array}$ \\
\hline Deviated wells & & & & \\
\hline Acid effect & & & & Effect on $\Sigma$ \\
\hline Lithology & & & & \\
\hline
\end{tabular}

constraints to the value of the $\mathrm{C} / \mathrm{O}$ tools. Table 1 summarizes the study outcome and the limitation of each technology.

Due to the porosity limitations, interpretation inconsistency, and complexity of using the $\mathrm{C} / \mathrm{O}$ technology in evaluating mixed-salinity reservoirs, many tried to find a second approach to solve the challenge.

\section{The second approach}

This approach is based on combining multiple measurements to solve for both the water saturation and the salinity in the mixed-salinity reservoirs.

In 2003, Webb et al. (2003) proposed the Log-InjectLog method to study the sweeping effectiveness of the low salinity water injection. The method is based on acquiring the Sigma log twice; the first is before the water injection while the second is after the water injection. The two sigma measurements are then overlaid for comparison. Since the LoSal water has lower sigma absorption compared to the original high salinity water, the separation between the two overlaid measurements determines the effectiveness of the LoSal sweeping efficiency. This is a qualitative method and cannot be used to quantitatively determine the current formation fluids' saturation.

In 2010, Minh (2011) used two measurements, the induction resistivity, and the formation sigma absorption in the wireline environment to calculate the formation water saturation in a mature carbonate field in the Middle East. To eliminate the borehole environment effects, e.g., invasion, on the sigma measurement since it is a shallow measurement, the sigma log was acquired after flowing the wells. The two measurements are simultaneously used, analytically 
and graphically, to solve for the formation water saturation and the water salinity.

In 2015, and like what Minh did in 2010, Li et al. (2015) proposed using the logging while drilling, LWD, Resistivity and Sigma measurements in open-hole to determine the fluids saturation in mixed-salinity reservoirs. The advantage of using the LWD measurement over the wireline, as in Minh, is to reduce the borehole environment effects on the sigma measurement. The two measurements provided two equations in two unknowns. The two equations are the water saturation equation using the resistivity log and the water saturation equation using the sigma absorption log. The two equations are simultaneously solved for $S_{w}$ and water salinity.

In this paper, a different approach to solve the mixedsalinity problem is investigated. The target of the research is to solve the challenge without the needs for special logging tools, combinations of logging tools or interpretation methods. The approach is investigated using forward modeling and core laboratory measurements. The lab measurements are performed in the core lab at American University in Cairo.

The methodology is based on treating the low salinity water with acid or alkaline before injection. This treatment results in.

1. Keeping the low salinity content of the injected water unchanged to maintain the value of the LoSal water injection in enhancing the reservoirs recovery factor

2. Decreasing the resistivity of the low salinity water to be equal to the original resistivity of high salinity formation water

The type and the volume of the acid or alkaline are carefully determined to achieve the target.

\section{The mixed-salinity forward modeling}

To demonstrate the mixed-salinity problems, challenges, errors in fluids saturation calculations and their economic impact on reservoir decisions, a forward model is developed based on a real reservoir structure from one of the North Africa Sandstone reservoirs, Figs. 1 and 2.

The forward model represents a layered reservoir with equal porosity, $\Phi=30 \%$, equal clay volume of $30 \%$ but with different permeability. The reservoir's original formation water salinity is $100 \mathrm{Kppm}$ and is injected with sea water, 35 Kppm salinity. The distribution of fluids in the pores before and after the LoSal water injection, Fig. 3, is modeled as

1. Before injection, the formation pores have $10 \%$ hydrocarbon and $90 \%$ original formation water

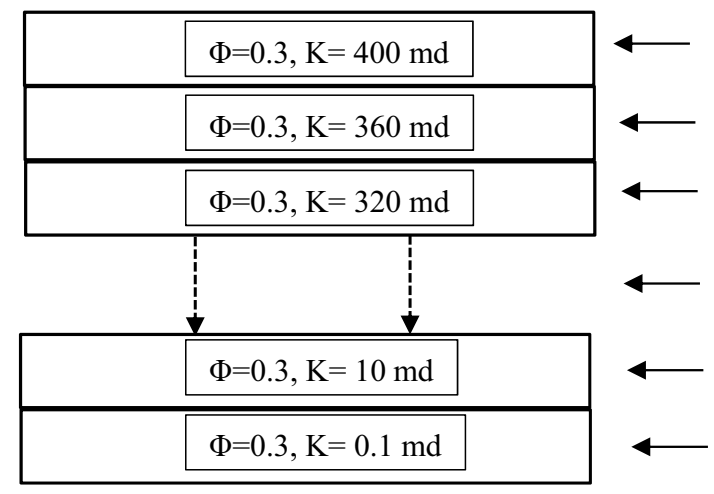

Fig. 1 Layered reservoir under LoSal injection

2. After injection with the sea water, the reservoir fluids became $60 \%$ hydrocarbon and $40 \%$ mixed-waters.

3. The $40 \%$ mixed-water is modeled using different percentages of the original water and the injected water due to the variations in the layers permeabilities, Table 2.

The calculations of the forward models are performed for two different wells as follows,

1. The first well represents an infill drilling, new well, where the open-hole resistivity log is modeled

2. The second well represents an observation well where the cased-hole sigma absorption is modeled

\section{The infill well case}

The forward modeled resistivity is calculated using the Simandoux (1982) water saturation model, Eqs. 1 and 2, to accommodate for the clay content

$S_{w}=\frac{a R_{w}}{2 \emptyset^{m}}\left[\sqrt{\left(\frac{V_{\mathrm{sh}}}{R_{\mathrm{sh}}}\right)^{2}+\frac{4 \emptyset^{m}}{a R_{w} R_{t}}}-\frac{V_{\mathrm{sh}}}{R_{\mathrm{sh}}}\right]$

$\frac{1}{R_{t}}=\frac{a R_{w}}{4 \emptyset^{m}}\left[\left(\frac{2 \emptyset^{m} S_{w}}{a R_{w}}+\frac{V_{\mathrm{sh}}}{R_{\mathrm{sh}}}\right)^{2}-\left(\frac{V_{\mathrm{sh}}}{R_{\mathrm{sh}}}\right)^{2}\right]$

The water resistivity of the original formation water and the injected sea water are calculated using Eqs. 3 and 4. Equation 3 provides the water resistivity at room temperature, $T_{1}$ in degree $\mathrm{F}$, using the water salinity

$R_{w T 1}=0.123+\frac{3647.5}{S^{0.995}}$

where $(S)$ is the salinity in ppm. Equation 4 provides the water resistivity under the reservoir temperature, $\mathrm{T}_{2}$, using the resistivity at the room temperature $T_{1}$. 

well
Fig. 2 North Africa sandstone
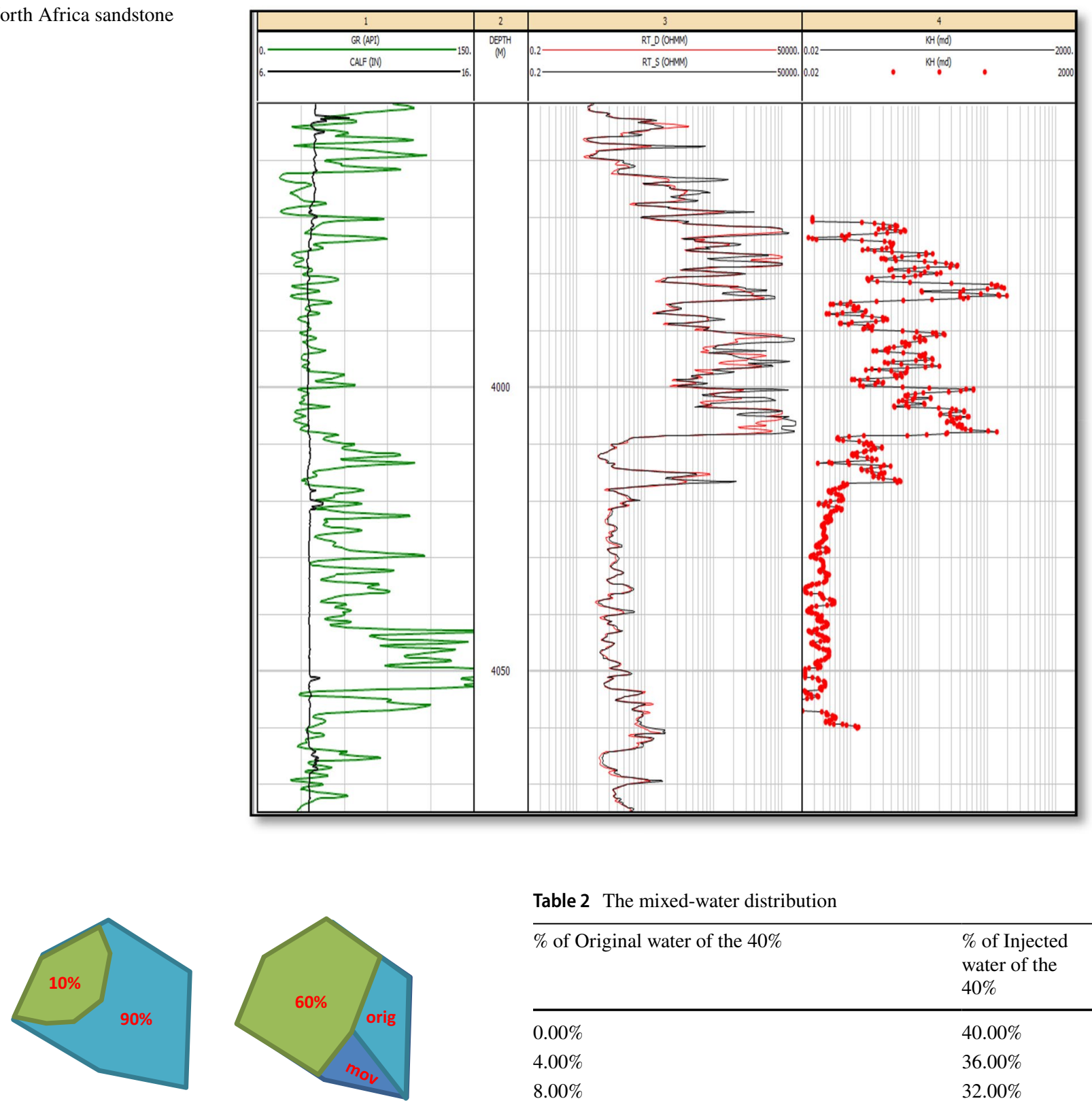

Fig. 3 Fluids distribution before and after LoSal water injection

$R_{w T 2}=R_{w T 1} \frac{T_{1}+6.77}{T_{2}+6.77}$

The calculated original formation water resistivity, $S=100,000 \mathrm{ppm}$, is $R_{w o}=0.0291 \mathrm{ohmm}$ while the injected water resistivity $R_{w i}=0.0783 \mathrm{ohmm}$ for the sea water, $35,000 \mathrm{ppm}$, for temperatures $T_{1}$ and $T_{2}$ as 75 and $200 \mathrm{~F}$, respectively.

To model the resistivity of the mixed-water salinity, the mixing law of conductivity is used, Eq. 5
Table 2 The mixed-water distribution

\begin{tabular}{ll}
\hline$\%$ of Original water of the $40 \%$ & $\begin{array}{l}\% \text { of Injected } \\
\text { water of the } \\
40 \%\end{array}$ \\
\hline $0.00 \%$ & $40.00 \%$ \\
$4.00 \%$ & $36.00 \%$ \\
$8.00 \%$ & $32.00 \%$ \\
$12.00 \%$ & $28.00 \%$ \\
$16.00 \%$ & $24.00 \%$ \\
$20.00 \%$ & $20.00 \%$ \\
$24.00 \%$ & $16.00 \%$ \\
$28.00 \%$ & $12.00 \%$ \\
$32.00 \%$ & $8.00 \%$ \\
$36.00 \%$ & $4.00 \%$ \\
$40.00 \%$ & $0.00 \%$ \\
\hline
\end{tabular}

$C_{\text {mix }}=\frac{C_{1} V_{1}+C_{2} V_{2}}{V_{1}+V_{2}}$ 
Table 3 The modeled resistivities

\begin{tabular}{llll}
\hline $\begin{array}{l}\text { Original water } \\
\text { volume } \%\end{array}$ & $\begin{array}{l}\text { Injected water } \\
\text { volume } \%\end{array}$ & $\begin{array}{l}\text { Mixed-salinity } \\
\text { Rw, Ohmm }\end{array}$ & $\begin{array}{l}\text { Formation } \\
\text { resistivity Rt }\end{array}$ \\
\hline $0.00 \%$ & $40.00 \%$ & 0.078 & 4.466 \\
$4.00 \%$ & $36.00 \%$ & 0.067 & 3.921 \\
$8.00 \%$ & $32.00 \%$ & 0.058 & 3.494 \\
$12.00 \%$ & $28.00 \%$ & 0.052 & 3.152 \\
$16.00 \%$ & $24.00 \%$ & 0.047 & 2.870 \\
$20.00 \%$ & $20.00 \%$ & 0.042 & 2.635 \\
$24.00 \%$ & $16.00 \%$ & 0.039 & 2.435 \\
$28.00 \%$ & $12.00 \%$ & 0.036 & 2.263 \\
$32.00 \%$ & $8.00 \%$ & 0.033 & 2.114 \\
$36.00 \%$ & $4.00 \%$ & 0.031 & 1.984 \\
$40.00 \%$ & $0.00 \%$ & 0.029 & 1.869 \\
\hline
\end{tabular}

where $C_{1}$ and $C_{2}$ are the conductivity of the original formation water and the injected water, respectively. The $V_{1}$ and $V_{2}$ are the volume of the original water and the injected water in the pores, respectively.

It is important to note that in real field applications, the calculation of the $R_{w}$ is more complicated to account for other minerals that may be dissolved in water. This is discussed in "Appendix 1".

Table 3 shows the forward modeled resistivity of the different percentages of the mixed-water, $R_{w}$, and the corresponding formation resistivity, $R_{t}$, using Eqs. 2 and 5.

\section{The forward model interpretation}

The modeled formation resistivities, $R_{t}$, is used to back calculate the hydrocarbon saturation, $S_{h c}$. Since there is no means of knowing the current $R_{w}$ using any available tools, the only two available options are.

1. Assume no injected water reached the pore, only oil is moved, and use the original formation water resistivity $R_{w o}=0.0291$ as $R_{w}$

2. Assume that the injected water flushed the pores and use the injected water resistivity $R_{w i}=0.0783 \mathrm{Ohmm}$ as $R_{w}$.

The calculations of the oil saturation for the two scenarios are shown in Table 4 and in Fig. 4. The forward model showed that the calculated hydrocarbon ranged between $60-75 \%$ when the original water resistivity is used as $R_{w}$ and underestimated, 36-60\%, if the injected water resistivity is used.
Table 4 The calculated hydrocarbon saturation

\begin{tabular}{lcll}
\hline $\begin{array}{l}\text { Percent } \\
\text { original } \\
\text { water }\end{array}$ & $\begin{array}{l}\text { Original } \\
\text { water volume } \\
\%\end{array}$ & $\begin{array}{l}\text { Hydrocarbon satu- } \\
\text { ration using Rwo }\end{array}$ & $\begin{array}{l}\text { Hydrocarbon } \\
\text { saturation using } \\
\text { Rwi }\end{array}$ \\
\hline $0.00 \%$ & $0.00 \%$ & $74.67 \%$ & $60.00 \%$ \\
$10.00 \%$ & $10.00 \%$ & $72.86 \%$ & $57.05 \%$ \\
$20.00 \%$ & $20.00 \%$ & $71.16 \%$ & $54.27 \%$ \\
$30.00 \%$ & $30.00 \%$ & $69.56 \%$ & $51.63 \%$ \\
$40.00 \%$ & $40.00 \%$ & $68.02 \%$ & $49.12 \%$ \\
$50.00 \%$ & $50.00 \%$ & $66.56 \%$ & $46.72 \%$ \\
$60.00 \%$ & $60.00 \%$ & $65.15 \%$ & $44.42 \%$ \\
$70.00 \%$ & $70.00 \%$ & $63.80 \%$ & $42.20 \%$ \\
$80.00 \%$ & $80.00 \%$ & $62.49 \%$ & $40.06 \%$ \\
$90.00 \%$ & $90.00 \%$ & $61.23 \%$ & $37.99 \%$ \\
$100.00 \%$ & $100.00 \%$ & $60.00 \%$ & $35.98 \%$ \\
\hline
\end{tabular}

\section{CALCULATED HYDROCARBON SATURATION}

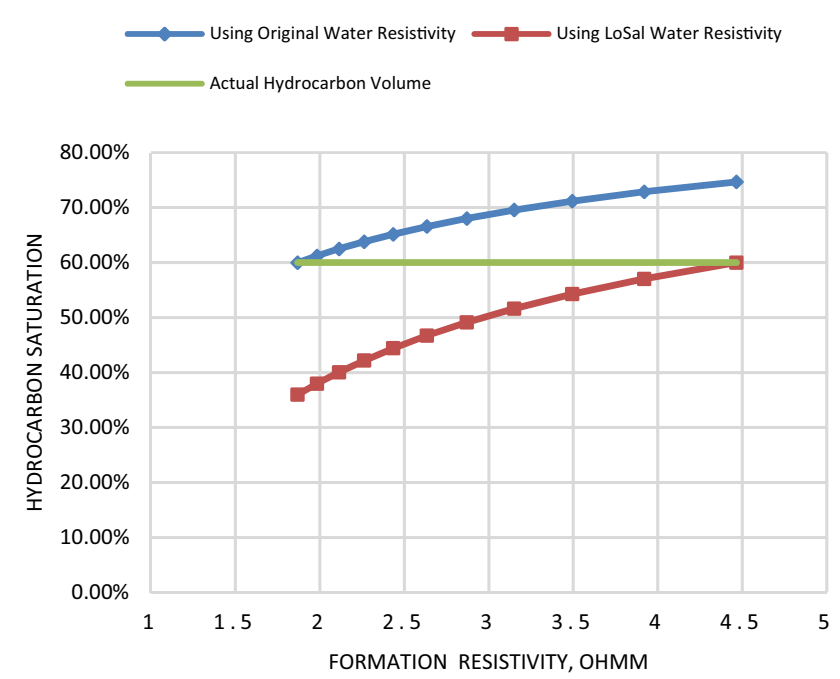

Fig. 4 The calculated hydrocarbon saturation
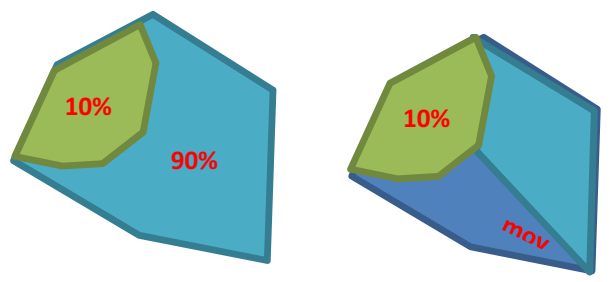

Fig. 5 No hydrocarbon movement case

\section{The worst-case scenario, the worst economic impact}

The case of no hydrocarbon moved to the pores, but only the injected water is the case that represents the most challenging and dangerous of all cases, Fig. 5, and Table 5 
Table 5 No hydrocarbon movement case

\begin{tabular}{llll}
\hline $\begin{array}{l}\text { Original water } \\
\text { volume } \%\end{array}$ & $\begin{array}{l}\text { Injected water } \\
\text { volume } \%\end{array}$ & $\begin{array}{l}\text { Mixed-salinity } \\
\mathrm{Rw}\end{array}$ & $\begin{array}{l}\text { Formation } \\
\text { resistivity Rt }\end{array}$ \\
\hline $0.00 \%$ & $90.00 \%$ & 0.078 & 0.979 \\
$9.00 \%$ & $81.00 \%$ & 0.067 & 0.848 \\
$18.00 \%$ & $72.00 \%$ & 0.058 & 0.748 \\
$27.00 \%$ & $63.00 \%$ & 0.052 & 0.669 \\
$36.00 \%$ & $54.00 \%$ & 0.047 & 0.606 \\
$45.00 \%$ & $45.00 \%$ & 0.042 & 0.553 \\
$54.00 \%$ & $36.00 \%$ & 0.039 & 0.509 \\
$63.00 \%$ & $27.00 \%$ & 0.036 & 0.471 \\
$72.00 \%$ & $18.00 \%$ & 0.033 & 0.438 \\
$81.00 \%$ & $9.00 \%$ & 0.031 & 0.410 \\
$90.00 \%$ & $0.00 \%$ & 0.029 & 0.385 \\
\hline
\end{tabular}

Table 6 The calculated hydrocarbon saturation

\begin{tabular}{lcll}
\hline $\begin{array}{l}\text { Percent } \\
\text { original } \\
\text { water }\end{array}$ & $\begin{array}{l}\text { Original } \\
\text { water volume } \\
\%\end{array}$ & $\begin{array}{l}\text { Hydrocarbon satu- } \\
\text { ration using Rwo }\end{array}$ & $\begin{array}{l}\text { Hydrocarbon } \\
\text { saturation using } \\
\text { Rwi }\end{array}$ \\
\hline $0.00 \%$ & $0.00 \%$ & $44.15 \%$ & $10.00 \%$ \\
$10.00 \%$ & $10.00 \%$ & $39.88 \%$ & $3.00 \%$ \\
$20.00 \%$ & $20.00 \%$ & $35.89 \%$ & $0.00 \%$ \\
$30.00 \%$ & $30.00 \%$ & $32.12 \%$ & $0.00 \%$ \\
$40.00 \%$ & $40.00 \%$ & $28.55 \%$ & $0.00 \%$ \\
$50.00 \%$ & $50.00 \%$ & $25.15 \%$ & $0.00 \%$ \\
$60.00 \%$ & $60.00 \%$ & $21.89 \%$ & $0.00 \%$ \\
$70.00 \%$ & $70.00 \%$ & $18.75 \%$ & $0.00 \%$ \\
$80.00 \%$ & $80.00 \%$ & $15.74 \%$ & $0.00 \%$ \\
$90.00 \%$ & $90.00 \%$ & $12.82 \%$ & $0.00 \%$ \\
$100.00 \%$ & $100.00 \%$ & $10.00 \%$ & $0.00 \%$ \\
\hline
\end{tabular}

In this case, an increase in the formation resistivity will be observed due to the movement of the high-resistivity LoSal water. Table 5 shows the forward modeling of the formation resistivity.

Since the real $R_{w}$ is unknown, the calculated hydrocarbon saturation using the two options, either the $R_{w o}$ or the $R_{w i}$ as the formation water resistivity $R_{w}$, is shown in Table 6 and Fig. 6. The hydrocarbon saturation, $S_{h c}$, varies between 10 and $44 \%$ when the $R_{w o}$ is used which will result in a decision to perforate the zone. If perforated, the zone will produce a $100 \%$ water and will require more spending to isolate the zone or squeeze the perforations.

\section{The forward model of the cased-hole well}

The cased-hole monitoring well is modeled using the same forward model reservoir used in the open-hole case, Fig. 1. In

\section{CALCULATED HYDROCARBON SATURATION}

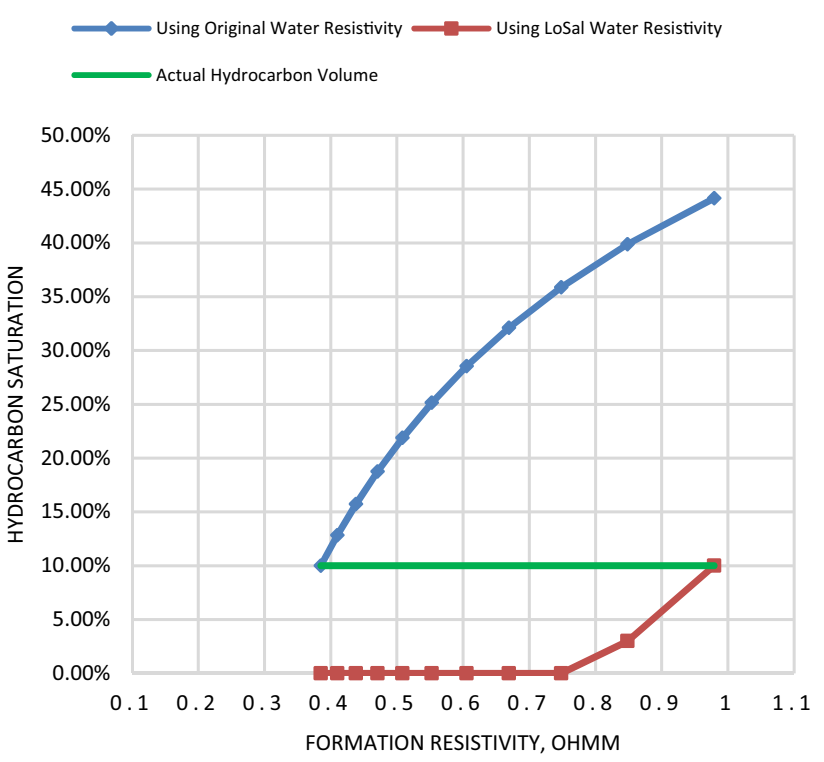

Fig. 6 The calculated hydrocarbon saturation

this case, the formation sigma absorption is calculated using the sigma absorption's volumetric equation, Eq. 6

$\Sigma_{t}=\emptyset S_{w} \Sigma_{w}+\emptyset\left(1-S_{w}\right) \Sigma_{o}+V_{c} \Sigma_{c}+\left(1-\emptyset-V_{c}\right) \Sigma_{m}$

where $\Sigma_{w}$ is the mixed-water absorption cross section; $\Sigma_{o}$ is the oil absorption cross section; $\Sigma_{c}$ is the clay absorption cross section; $\Sigma_{m}$ is the matrix absorption cross section.

The water sigma absorption $\Sigma_{\mathrm{w}}$ is salinity dependent and is calculated using Eq. 7, Crane's (1999) petrophysics handbook

$\sum_{w}=22+0.000404 * S$

where $S$ is the water salinity in ppm.

The absorption cross section of the mixed-salinity water is calculated using the volumetric equation, Eq. 8, where $V_{w o}$ is the volume of the original water in the pore, $V_{w i}$ is the volume of the injected water in the pore, $\Sigma_{w o}$ is the absorption cross of the original water, $100,000 \mathrm{ppm}$, and $\Sigma_{w i}$ is the absorption cross section of the injected water, 35,000 ppm.

$\sum_{w}=V_{w o} \sum_{w o}+V_{w i} \sum_{w i}$

The oil absorption cross section is 22.2 capture units and the clay absorption cross section is assumed to be 40 capture units based on the handbooks of the service companies. 
Table 7 The calculated hydrocarbon saturation

\begin{tabular}{llll}
\hline $\begin{array}{l}\text { Formation } \\
\text { sigma CU }\end{array}$ & $\begin{array}{l}\text { Sw using original } \\
\text { water sigma }\end{array}$ & $\begin{array}{l}\text { Sw using LoSal } \\
\text { water sigma }\end{array}$ & $\begin{array}{l}\text { Actual hydro- } \\
\text { carbon volume }\end{array}$ \\
\hline 23.13 & $86.13 \%$ & $60.00 \%$ & $60.00 \%$ \\
23.45 & $83.52 \%$ & $52.57 \%$ & $60.00 \%$ \\
23.76 & $80.90 \%$ & $45.14 \%$ & $60.00 \%$ \\
24.08 & $78.29 \%$ & $37.71 \%$ & $60.00 \%$ \\
24.39 & $75.68 \%$ & $30.29 \%$ & $60.00 \%$ \\
24.71 & $73.06 \%$ & $22.86 \%$ & $60.00 \%$ \\
25.02 & $70.45 \%$ & $15.43 \%$ & $60.00 \%$ \\
25.34 & $67.84 \%$ & $8.00 \%$ & $60.00 \%$ \\
25.65 & $65.23 \%$ & $0.57 \%$ & $60.00 \%$ \\
25.97 & $62.61 \%$ & $0.00 \%$ & $60.00 \%$ \\
26.28 & $60.00 \%$ & $0.00 \%$ & $60.00 \%$ \\
\hline
\end{tabular}

\section{CALCULATED HYDROCARBON SATURATION}

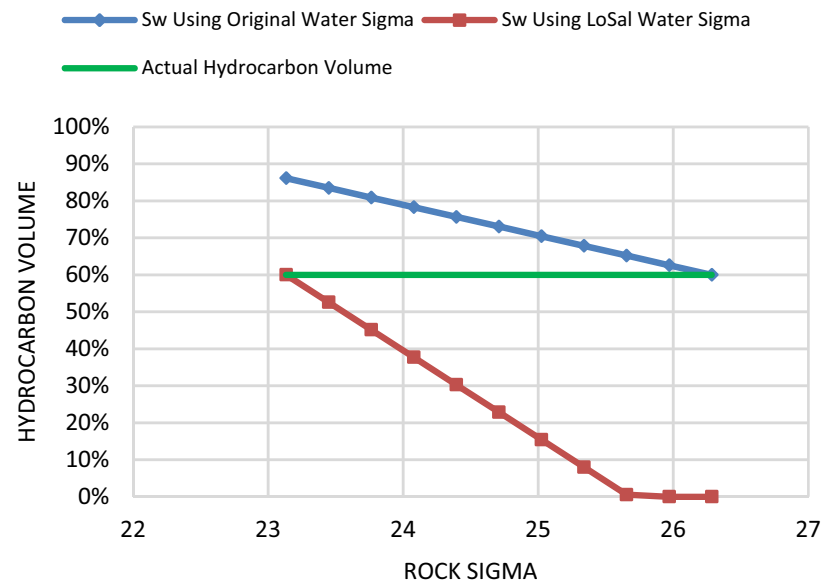

Fig. 7 The calculated hydrocarbon saturation

\section{The forward model interpretation}

The modeled formation sigma, $\Sigma_{t}$, is used to calculate the hydrocarbon saturation, $S_{h c}$, for the case of oil and injected water movement, Fig. 3.

Like the resistivity case and since there is no means of knowing the current $\Sigma_{w}$ using any available tools, the only two options available for the analysis are.

1. Assume no injected water reached the pore, only oil is moved, and use the original formation water sigma absorption $\Sigma_{w o}=62.4 \mathrm{CU}$ as $\Sigma_{w}$

2. Assume that the injected water reached the pores and filled the water portion then use the injected water sigma $\Sigma_{w i}=36.14 \mathrm{CU}$ as $\Sigma_{w}$.
Table 8 The calculated hydrocarbon saturation

\begin{tabular}{llll}
\hline $\begin{array}{l}\text { Formation } \\
\text { sigma CU }\end{array}$ & $\begin{array}{l}\text { Sw using original } \\
\text { water sigma }\end{array}$ & $\begin{array}{l}\text { Sw using LoSal } \\
\text { water sigma }\end{array}$ & $\begin{array}{l}\text { Actual hydro- } \\
\text { carbon volume }\end{array}$ \\
\hline 25.22 & $68.79 \%$ & $10.00 \%$ & $10.00 \%$ \\
25.93 & $62.91 \%$ & $0.00 \%$ & $10.00 \%$ \\
26.64 & $57.03 \%$ & $0.00 \%$ & $10.00 \%$ \\
27.35 & $51.15 \%$ & $0.00 \%$ & $10.00 \%$ \\
28.06 & $45.27 \%$ & $0.00 \%$ & $10.00 \%$ \\
28.77 & $39.40 \%$ & $0.00 \%$ & $10.00 \%$ \\
29.48 & $33.52 \%$ & $0.00 \%$ & $10.00 \%$ \\
30.19 & $27.64 \%$ & $0.00 \%$ & $10.00 \%$ \\
30.90 & $21.76 \%$ & $0.00 \%$ & $10.00 \%$ \\
31.60 & $15.88 \%$ & $0.00 \%$ & $10.00 \%$ \\
32.31 & $10.00 \%$ & $0.00 \%$ & $10.00 \%$ \\
\hline
\end{tabular}

\section{CALCULATED HYDROCARBON SATURATION}

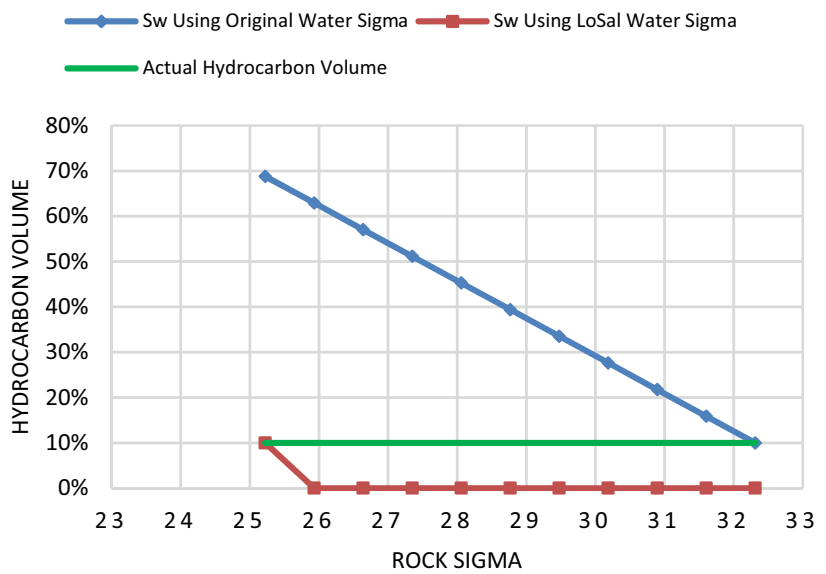

Fig. 8 The calculated hydrocarbon saturation

The calculations of the oil saturation for the two scenarios are shown in Table 7 and Fig. 7. The forward model showed that the calculated hydrocarbon will be overestimated when the original water sigma is used as $\Sigma_{w}$ and underestimated if the injected water sigma is used.

\section{The worst-case scenario}

The calculated hydrocarbon saturation using the $\Sigma_{w o}$ and $\Sigma_{w i}$ as the formation water sigma is shown in Table 8 and Fig. 8 for the worst-case scenario of no hydrocarbon movement but only the injected water, Fig. 5. The hydrocarbon saturation, $S_{h c}$, shows an increase up to $69 \%$, when using the original sigma water, $\Sigma_{w o}$ as the $\Sigma_{w}$ which will result in a decision to perforate the zone. If perforated, the zone will produce a $100 \%$ water and will require more spending to isolate the zone or squeeze the perforations like the open-hole case. 


\section{The proposed solution}

The proposed solution is based on treating the low salinity water, before injection, with acid or alkaline. This treatment has the advantages of.

1. Keeping the low salinity content of the injected water unchanged. This will maintain the value of the LoSal injection in enhancing the recovery factor

2. Decreasing the resistivity of the low salinity water to the level of the original formation water resistivity. This will eliminate the mixed-salinity effect

\section{The lab testing of the proposed solution}

All experiments are performed in the core laboratory. The equipment used throughout the testing are shown in "Appendix 2". Multiple measurements are performed on actual core plugs, Sandstone rock, using different mixtures of hydrocarbon, original high-salinity formation water and low salinity injection water simulating the mixed-salinity challenges. The same experiments are then repeated but with replacing the low salinity injection water with the treated low salinity injection water to test its applicability in solving the mixedsalinity challenge. The fluids used in the experiments are.

1. A $100 \mathrm{Kppm}$ salt-water representing the high-salinity original formation water.

2. A $35 \mathrm{Kppm}$ salt-water representing the low salinity injection water.

3. A $20 \% \mathrm{HCl}$ acid concentration is used to prepare the acid treated low salinity injection water.

The core plugs are cut in the laboratory from an available sandstone core. The preparation of the core plugs, the original high-salinity formation water, the low salinity injection water, and the acid treatment low salinity injection water are discussed in the next sections. All measurements are performed under the ambient conditions because the high pressure and high temperature capabilities are not available at the laboratory of the American University in Cairo.

Table 9 Samples physical properties

\begin{tabular}{lrrrr}
\hline Property & \multicolumn{1}{l}{ l } & \multicolumn{1}{l}{ l } \\
\hline Weight (g) & 60.30 & 60.58 & 59.92 & 60.07 \\
Length (mm) & 65.69 & 65.63 & 65.89 & 65.54 \\
Diameter (mm) & 25.24 & 25.18 & 25.03 & 25.27 \\
Bulk volume (cc) & 32.87 & 32.68 & 32.42 & 32.87 \\
Pore volume (cc) & 10.36 & 9.95 & 9.95 & 10.35 \\
Porosity (\%) & 31.52 & 30.45 & 30.69 & 31.49 \\
Gas permeability (md) & 723.22 & 669.12 & 743.68 & 737.30 \\
\hline
\end{tabular}

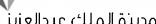

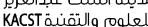

Table 10 Samples physical properties

\begin{tabular}{lrrrr}
\hline Property & \multicolumn{1}{l}{5} & \multicolumn{1}{l}{7} & \multicolumn{1}{l}{8} \\
\hline Weight (g) & 59.63 & 59.89 & 59.33 & 59.57 \\
Length (mm) & 65.38 & 65.71 & 65.52 & 65.67 \\
Diameter (mm) & 25.17 & 25.14 & 25.08 & 25.13 \\
Bulk volume (cc) & 32.53 & 32.62 & 32.37 & 32.57 \\
Pore volume (cc) & 10.11 & 10.08 & 10.04 & 10.27 \\
Porosity (\%) & 31.08 & 30.90 & 31.02 & 31.53 \\
Gas permeability (md) & 782.38 & 722.49 & 737.20 & 825.11 \\
\hline
\end{tabular}

\section{The preparation steps}

a. The Core Plugs

1. Several core plugs from the same core are cut

2. All physical properties, length, diameter, porosity, perm, etc., are measured. The Helium porosimeter- matrixcup- and Pore volume and porosity were calculated based on grain volume measurement

3. The plugs that have similar physical properties, Tables 9 and 10 , are chosen, for the experiments, to avoid any sources of biasing during the testing of the proposed solution.

b. The Original and the Injection Waters

1. Water samples are prepared using distilled water and $\mathrm{NaCl}$ pure salt. The first fluid is the $100 \mathrm{Kppm}$ salinity water, representing the original formation water, and the second is the $35 \mathrm{Kppm}$ salinity water representing the LoSal injection water.

2. The resistivities of the waters are measured using the fluids resistivity prob

3. The resistivities of the $100 \mathrm{Kppm}$ and the $35 \mathrm{Kppm}$ waters are $0.193 \mathrm{Ohmm}$ and $0.338 \mathrm{Ohmm}$, respectively

c. The Treated Water

1. Hydrochloric acid, $\mathrm{HCl} 20 \%$ concentration, is used. The $\mathrm{HCl}$ is used here since the formation is sandstone.

2. The conductivity mixing law, Eq. 5, is used to calculate the volume of the acid required to decrease the 35 $\mathrm{Kppm}$ water resistivity to be equal to the $100 \mathrm{Kppm}$ water resistivity.

3. The calculated acid volume is mixed with the $35 \mathrm{Kppm}$ water and its resistivity is measured to compare to the $100 \mathrm{Kppm}$ water to ensure that both are equal

The required volume of the hydrochloric acid to lower the resistivity from $0.338 \mathrm{Ohmm}$ to $0.193 \mathrm{Ohmm}$, equivalent to the $100 \mathrm{Kppm} \mathrm{NaCl}$ original water is determined using the mixing law, Eq. 5. It is found that $27 \mathrm{CC}$ of the acid per a liter of $35 \mathrm{Kppm}$ water is the volume required. The conductivity of the $20 \%$ hydrochloric acid (Invensys Foxboro) is $85 \mathrm{mho} / \mathrm{m}$. 
Table 11 Mixing law vs. measured resistivities

\begin{tabular}{lcll}
\hline $\begin{array}{l}\text { 100 Kppm } \\
\text { water volume, } \\
\text { CC }\end{array}$ & $\begin{array}{l}\text { 35 Kppm-treated } \\
\text { water volume, } \\
\text { CC }\end{array}$ & $\begin{array}{l}\text { Lab meas- } \\
\text { ured Res } \\
\text { Ohmm }\end{array}$ & Mixing law Ohmm \\
\hline 200 & 0 & 0.19342 & 0.19300 \\
160 & 40 & 0.19394 & 0.19324 \\
120 & 80 & 0.19446 & 0.19347 \\
80 & 120 & 0.19446 & 0.19370 \\
40 & 160 & 0.19446 & 0.19394 \\
0 & 200 & 0.19446 & 0.19417 \\
\hline
\end{tabular}

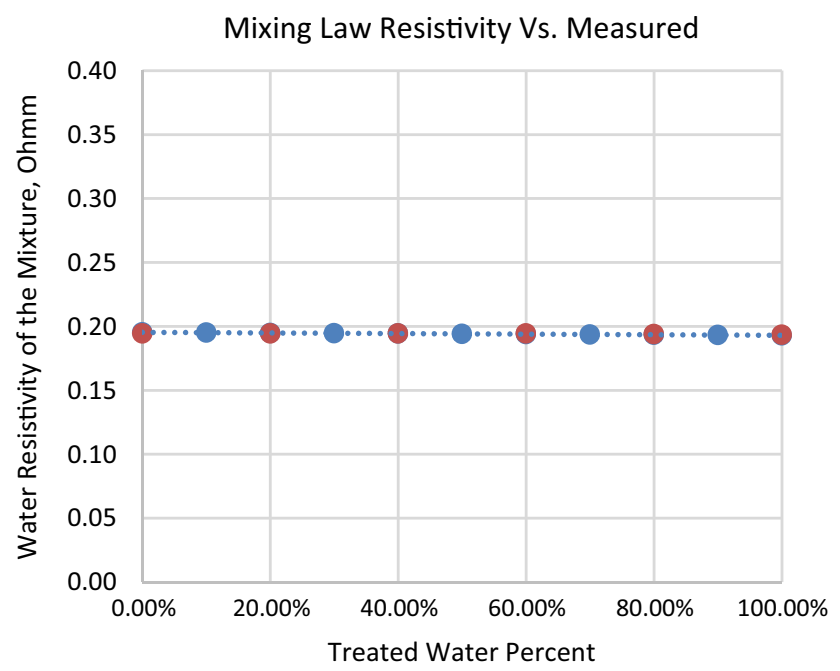

Fig. 9 Measured vs. modeled resistivity

To test the accuracy of the mixing law, Eq. 5, in predicting the volume of the acid, the resistivity of multiple mixtures of the $100 \mathrm{Kppm}$ water and the treated $35 \mathrm{Kppm}$ water are measured in the laboratory using the resistivity probe, and compared to the calculated resistivities using the mixing law. The comparisons are shown in Table 11 and Fig. 9. It is confirmed that the mixing law is adequate.

\section{The testing procedure}

The prepared plugs and fluids are used to test the applicability of the acid-treated water in solving the mixedsalinity reservoir challenges. Four cases are shown here as follows

1. Case 1: This case represents the no hydrocarbon movements but fully saturated zone with a mixture of different percentages of the original formation water and the low
Table $12100 \mathrm{Kppm}$ water case

\begin{tabular}{lll}
\hline Water volume & 7.7 & $\mathrm{Cc}$ \\
Rw injected & 0.193 & $\mathrm{Ohmm}$ \\
Core plug resistance, Ohm & 124.5 & Ohm \\
Core plug resistivity, Ohmm & 0.932804 & Ohmm \\
\hline
\end{tabular}

Table $1335 \mathrm{Kppm}$ water

\begin{tabular}{lll}
\hline Water volume & 7.8 & cc \\
Rw injected & 0.338 & Ohmm \\
Core plug resistance, Ohm & 276.3 & Ohm \\
Core Plug Resistivity, Ohmm & 2.070151 & Ohmm \\
\hline
\end{tabular}

Table 14 50/50 $35 \mathrm{Kppm}+100 \mathrm{Kppm}$

\begin{tabular}{lll}
\hline Water volume & 7.8 & $\mathrm{cc}$ \\
Rw injected & 0.246 & Ohmm \\
Core plug resistance, Ohm & 212.2 & Ohm \\
Core plug resistivity, Ohmm & 1.589888 & Ohmm \\
\hline
\end{tabular}

salinity injecting water and the water volume is measured. Three results are shown here

a. The plug is saturated with a single fluid, $100 \mathrm{Kppm}$ water representing before injection case

b. The plug is saturated with LoSal injection water, 35 Kppm, representing full sweeping

c. The plug is saturated using 50/50 mixture of the 100 $\mathrm{Kppm}$ original water and the $35 \mathrm{Kppm}$ LoSal water representing partial sweeping

a. Discussion: The measured core plug resistivity of the $35 \mathrm{Kppm}$ water, Table 13, shows higher resistivity compared to the $100 \mathrm{Kppm}$ one, Table 12

b. The measured core plug resistivity of the 50/50 mixture, Table 14, shows higher resistivity compared to the 100 Kppm, Table 12

The above measurements confirm the effect of the low salinity water injection in increasing the formation resistivity even when no hydrocarbon is moved. In formation evaluation, this will be misinterpreted as hydrocarbon movement. This, in turn, will result in wrong perforation decisions. This case was discussed in the section of the forward modeling and marked as "Worst-Case Scenario".

2. Case 1.1: The tests in Case 1 (c) is repeated but with replacing the low saline water with the treated low saline 
Table 15 50/50 Treated $35 \mathrm{Kppm}$ and $100 \mathrm{KPPM}$

\begin{tabular}{lll}
\hline Water volume & 7.7 & $\mathrm{cc}$ \\
$\mathrm{Rw}$ injected & 0.204 & $\mathrm{ohmm}$ \\
Core plug resistance, Ohm & 132.1 & $\mathrm{Ohm}$ \\
Core plug resistivity, Ohmm & 0.949746 & Ohmm \\
\hline
\end{tabular}

Table $16100 \mathrm{Kppm}$ and Synthetic oil

\begin{tabular}{lll}
\hline Oil volume & 1.5 & $\mathrm{cc}$ \\
Water volume & 6.2 & $\mathrm{cc}$ \\
Rw injected & 0.193 & $\mathrm{Ohmm}$ \\
Core plug resistance, Ohm & 204.3 & $\mathrm{Ohm}$ \\
Core plug resistivity, Ohmm & 1.530698 & $\mathrm{Ohmm}$ \\
\hline
\end{tabular}

Table $1735 \mathrm{Kppm}$ and Synthetic oil

\begin{tabular}{lll}
\hline Oil volume & 1.5 & $\mathrm{cc}$ \\
Water volume & 6.3 & $\mathrm{cc}$ \\
Rw injected & 0.338 & $\mathrm{Ohmm}$ \\
Core plug resistance, Ohm & 478.2 & $\mathrm{Ohm}$ \\
Core plug resistivity, Ohmm & 3.582866 & $\mathrm{Ohmm}$ \\
\hline
\end{tabular}

Table $1835 \mathrm{Kppm}$ treated and synthetic oil

\begin{tabular}{lll}
\hline Oil volume & 1.5 & $\mathrm{cc}$ \\
Water volume & 6.2 & $\mathrm{cc}$ \\
Rw injected & 0.204 & Ohmm \\
Core plug resistance, Ohm & 198.2 & Ohm \\
Core plug resistivity, Ohmm & 1.484994 & Ohmm \\
\hline
\end{tabular}

water. If the proposed solution is applicable, this resistivity should be equal to the $100 \mathrm{Kppm}$ case Case 1 (a). Discussion: The measured core plug resistivity of the 50/50 mixture of the " $35 \mathrm{Kppm}$ Treated water and the $100 \mathrm{Kppm}$ original water", Table 15 , compared to the $100 \mathrm{Kppm}$ water, Table 12, show resistivity values within $2 \%$ difference. This comparison confirms that the treated low salinity water resolves the mix-salinity challenge for the worst-case scenario.

3. Case 2: The tests in Case 1 are repeated but with oil and water instead of only water. These tests represent the sweeping of hydrocarbon and the LoSal injection water. Two measurements are shown here

a. The plug is saturated with $1.5 \mathrm{cc}$ oil $(0.927 \mathrm{~g} / \mathrm{cc}$ density $)$ and $100 \mathrm{Kppm}$

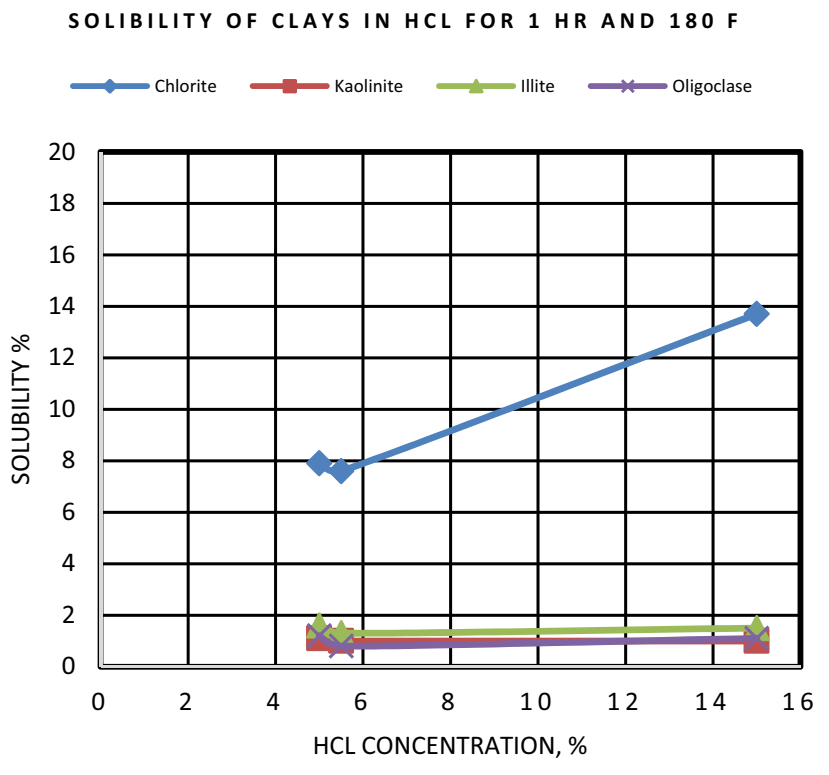

Fig. 10 Solubility tests on clays

b. The plug is saturated with $1.5 \mathrm{cc}$ oil and LoSal injection water, $35 \mathrm{Kppm}$. Discussion: The measured core plug resistivity of the $35 \mathrm{Kppm}$ water with oil, Table 17, shows higher resistivity compared to the oil and 100 Kppm water, Table 16. This confirms the effect of the low salinity water injection in increasing the formation resistivity. This will result in overestimating the hydrocarbon volume.

Case 2.1: The tests in Case 2 is repeated but with using the treated injection water.

Discussion: The measured core plug resistivity of the "35 Kppm-Treated water with oil", Table 18, and the 100 Kppm original water with oil”, Table 16, show similar resistivity values within $3 \%$ accuracy. This comparison confirms that the treated low salinity.

water resolves the mix-salinity challenge.

\section{The monitoring cased-hole wells solution}

The proposed solution for the cased-hole monitoring wells is to use the through casing resistivity measurement instead of the sigma measurement. Since the treated low salinity water injection will maintain the mixed-salinity reservoirs water resistivity unchanged, equal to the original formation water resistivity, the through casing resistivity will provide the most accurate solution compared to the currently used solutions, $\mathrm{C} / \mathrm{O}$ and Sigma. 


\section{Effect of acid treatment on clay minerals}

A study on the effects of different concentrations of the hydrochloric acid on the different clay types under variable temperature and time was performed by Simon and Anderson (1990) for the acid treatment purposes. The study was performed on four major clay types, Illite, Kaolinite, Chlorite and Oligoclase. The solubility test performed on the four clay types showed that the $\mathrm{HCl}$ effect on clay solubility is very minor and it decreases with the decrease of the acid concentration. Chlorite has the highest solubility at the $15 \%$ $\mathrm{HCl}$ concentration due to its iron component (Fig. 10).

In the LoSal application case, the acid concentration required to lower the LoSal water is much lower than even the $3 \%$ shown in Simon et al. study. The acid concentration used in the LoSal water injection treatment can be calculated as.

1. $27 \mathrm{cc}$ of $20 \% \mathrm{HCl}$ acid has only $540 \mathrm{ppm}$ of $\mathrm{HCl}$ by weight

2. The concentration of the treated LoSal water will then have $0.054 \% \mathrm{HCl}$ concentration.

This is a very low acid concentration to raise any concerns regarding the effect on formation clays.

\section{Conclusion}

The proposed solution of treating the low salinity water using acid or alkaline prior to injection is investigated and proved to be a practical solution to the formation evaluation challenges. The treatment lowered the resistivity of the water to the same level of the original formation water without changing its low salinity. The required volume of acid to lower the LoSal resistivity is very small, few cubic centimeters, which will not have any damage to formation lithology including clay minerals.

Funding The author(s) received no specific funding for this work.

\section{Compliance with ethical standards}

Conflict of interest The authors hereby confirm no conflict of interest in this publication regarding any financial or personal relationship with a third party whose interests could be positively or negatively influenced by the article's conte.

Ethical statement The authors hereby confirm abiding with all ethics including copy rights, trademarks, commercial statements, etc.

Open Access This article is licensed under a Creative Commons Attribution 4.0 International License, which permits use, sharing, adaptation, distribution and reproduction in any medium or format, as long as you give appropriate credit to the original author(s) and the source, provide a link to the Creative Commons licence, and indicate if changes were made. The images or other third party material in this article are included in the article's Creative Commons licence, unless indicated otherwise in a credit line to the material. If material is not included in the article's Creative Commons licence and your intended use is not permitted by statutory regulation or exceeds the permitted use, you will need to obtain permission directly from the copyright holder. To view a copy of this licence, visit http://creativecommons.org/licenses/by/4.0/.

\section{Appendix 1}

The formation water resistivity is calculated using the Total Dissolved Solids, TDS. The dissolved minerals are obtained from the water laboratory mineral composition analysis. The TDS is calculated using as

$\operatorname{TDS}=\sum_{i=1}^{n} S_{1}$

where $S_{i}$ is the ion concentration of element (i) in ppm. The TDS is then used to calculate the elements' multipliers, $S_{\text {imult }}$, using the chart (courtesy of Schlumberger). The sodium chloride equivalence of all minerals, $\mathrm{NaCl}_{\mathrm{eq}}$ is then calculated as

$\mathrm{NaCl}_{\text {eq }}=\sum_{i=1}^{N} S_{\text {imult }} * S_{i}$

The $\mathrm{NaCl}_{\text {eq }}$ is then used in Eqs. 1 and 2 to determine the water resistivity. 


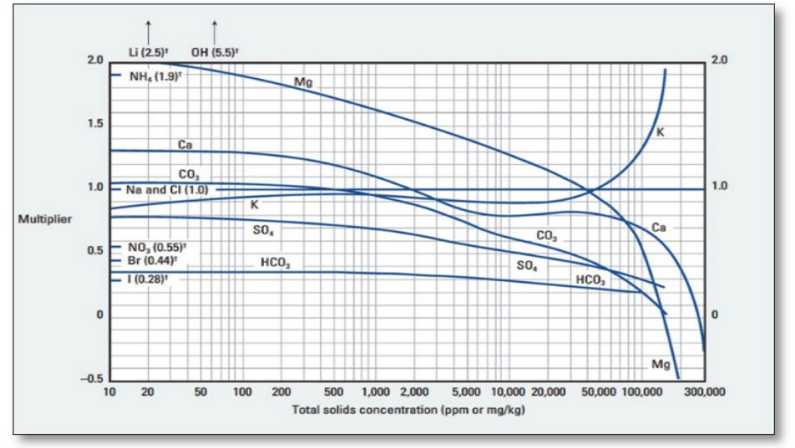

The Total Dissolved Solids chart

\section{Appendix 2}

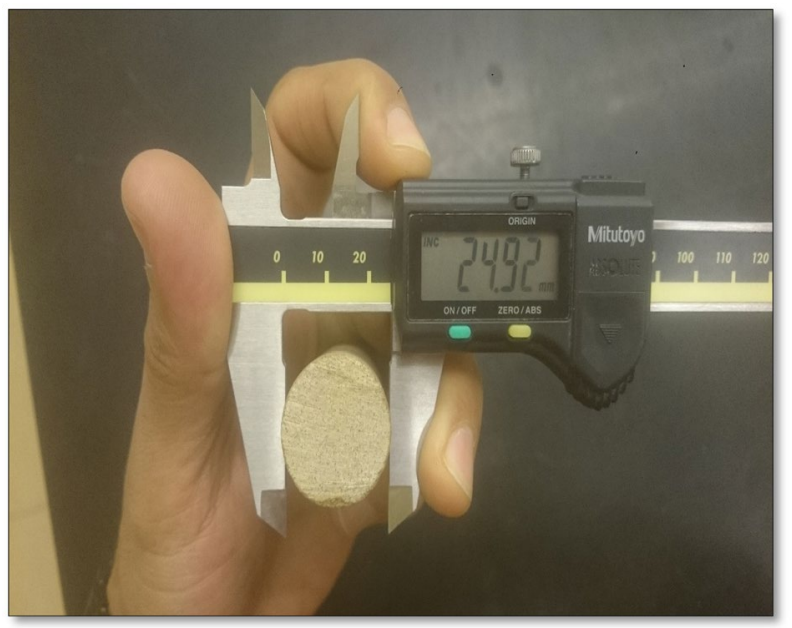

The Micrometer

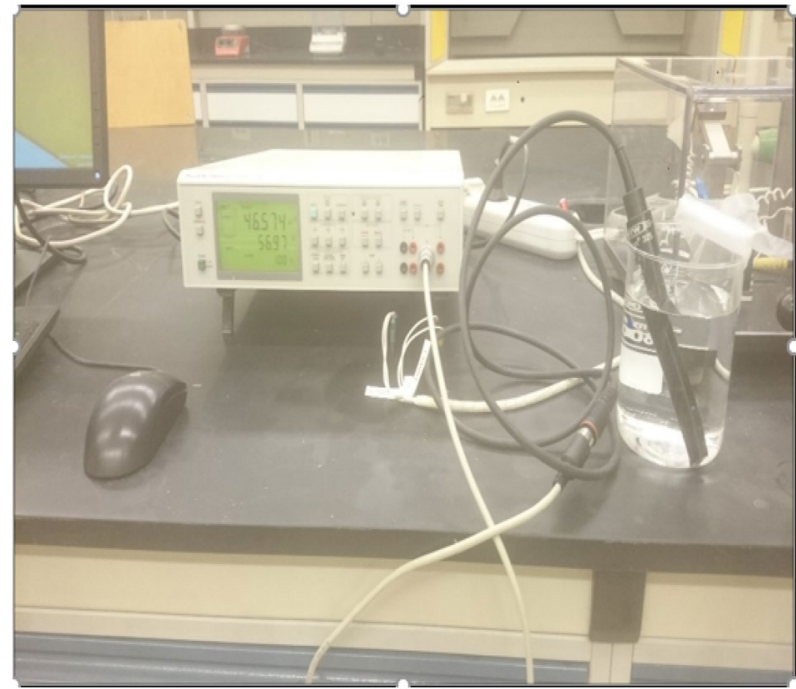

The Fluid Resistivity Prob

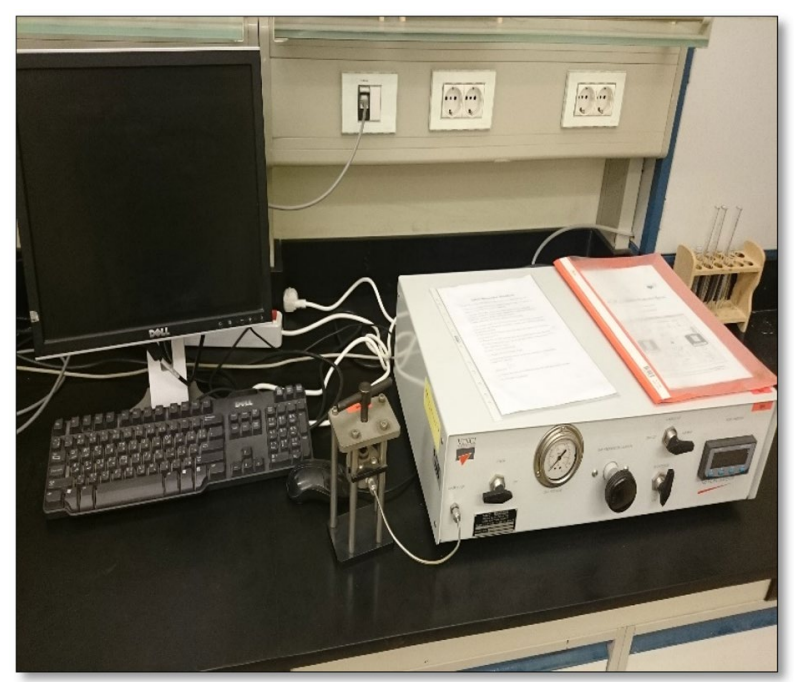

The Porosimeter 


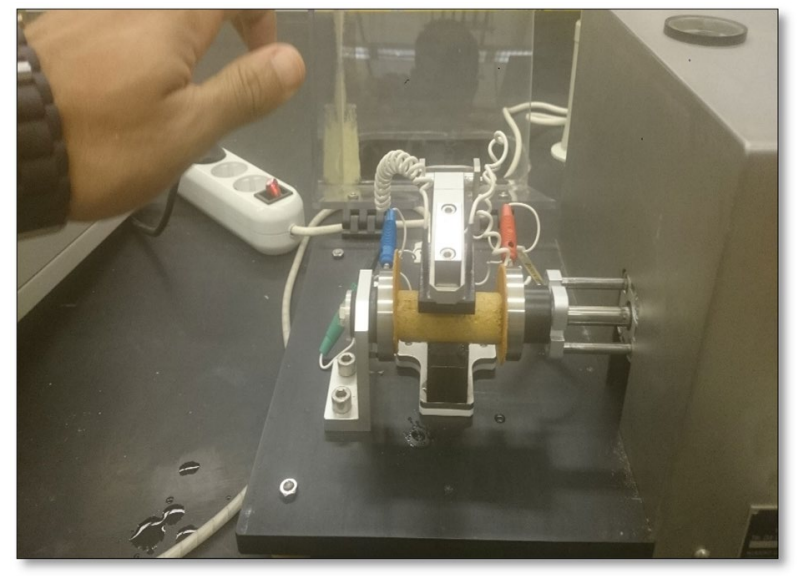

Core Plug Resistivity prob

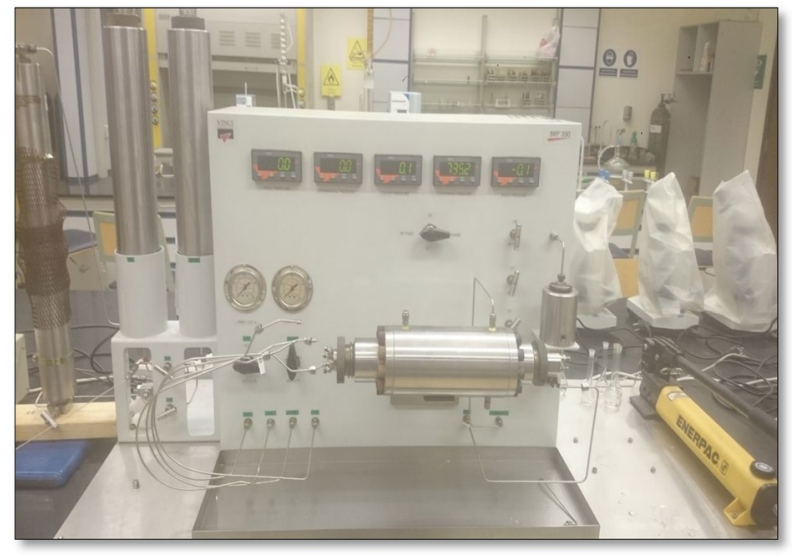

The Fluid ljection

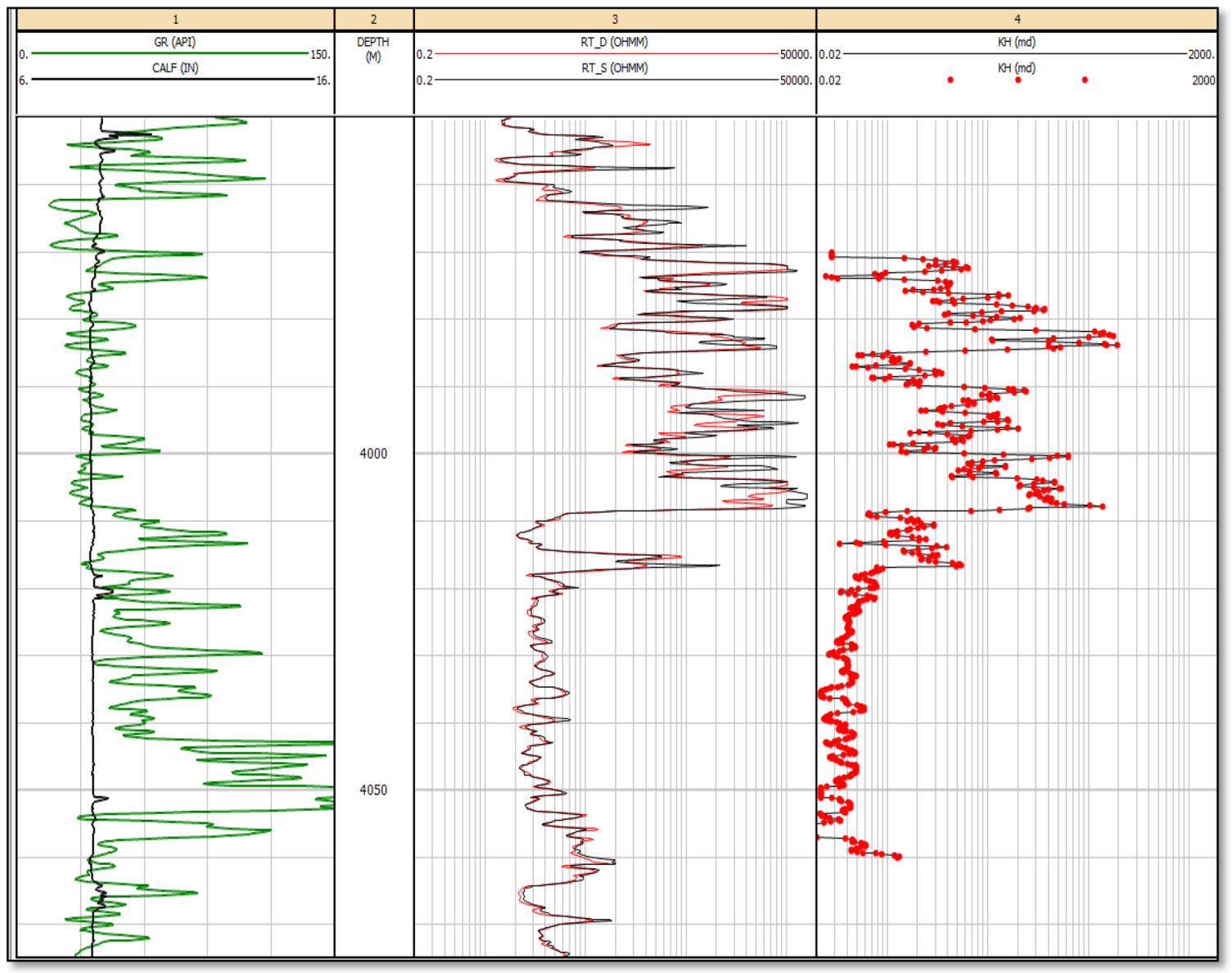




\section{References}

Crain's Petrophysical Handbook, internet version (1999)

Eyvazzadeh RY, Kelder O, Al-Hajari AA, Ma S, Al-Behair AM (2004)

Modern carbon/oxygen logging methodologies: comparing hydrocarbon saturation determination techniques. In: Paper SPE 90339

Freeman DW, Fenn CJ (1989) An evaluation of various logging methods for the determination of remaining oil saturation in a mixedsalinity environment. SPE 17976.

Invensys Foxboro, Massachusetts Price Sheet 6-3PREF, Page 1

Li T, Han S, Han S, Liu Y, Li H, Lei J (2015) Improving rock and fluid characterization in complex water flooded reservoirs with LWD resistivity and sigma logs. SPWLA

Ma SM, Al-Hajari AA, Berberian G, Ramamoorthy R (2005) Cased hole reservoir saturation monitoring in mixed salinity environments: a new integrated approach. SPE 92426
Minh C (2011) Combining resistivity and capture sigma logs for formation evaluation in unknown water salinity: a case study in a mature carbonate field. SPE 135160

Simandoux P (1982) Dielectric measurements in porous media and applications in Shaly Formations. Revue de l'Institute Francais de Petrole: SPWLA English Translation Volume Shaly Sand

Simon D, Anderson MS (1990) Stability of clay minerals in acid. SPE 19422

Webb C, Black J, Al-Jaleel H (2003) Low salinity oil recovery: loginject-log. SPE-81460

Publisher's Note Springer Nature remains neutral with regard to jurisdictional claims in published maps and institutional affiliations. 